\title{
Enhanced extraction of phenolic compounds from coffee industry's residues through solid state fermentation by Penicillium purpurogenum
}

\author{
Lady Rossana PALOMINO García ${ }^{1 *}$, Carolina Rabal BIASETTO², Angela Regina ARAUJO², \\ Vanildo Luiz Del BIANCHI ${ }^{1}$
}

\begin{abstract}
The use of agroindustrial residues is an economical solution to industrial biotechnology. Coffee husk and pulp are abounding residues from coffee industry which can be used as substrates in solid state fermentation process, thus allowing a liberation and increase in the phenolic compound content with high added value. By employing statistical design, initial moisture content, $\mathrm{pH}$ value in the medium, and the incubation temperature were evaluated, in order to increase the polyphenol content in a process of solid state fermentation by Penicillium purpurogenum. The main phenolic compounds identified through HPLC in fermented coffee residue were chlorogenic acid, caffeic acid, and rutin. Data obtained through HPLC with the radical absorbance capacity assay suggest the fermented coffee husk and pulp extracts potential as a source of phenolic acids and flavonoids. Results showed good perspectives when using $P$. purpurogenum strain to enhance the liberation of phenolic compounds in coffee residues.
\end{abstract}

Keywords: coffee husk; coffee pulp; filamentous fungi; bioprocess design; antioxidant activity; chlorogenic acid.

Practical Application: This study evaluated the influence of solid state fungal fermentation in obtaining polyphenols. Thus, it determined the total phenols content, identifying and quantifying the main phenolic compounds, and it determined the antioxidant activity through the effective concentration $\left(\mathrm{EC}_{50}\right)$ of the extracts.

\section{Introduction}

Agroindustrial residues use has been proving to be an alternative solution when obtaining bioactive compounds, since most of it still contains interesting molecules which can be extracted and used in different areas of application. The coffee industry generates high amounts of residues, since coffee is one of the most consumed beverages in the world, besides being the second most traded commodity, after petroleum (Mussatto et al., 2011; Esquivel \& Jiménez, 2012). Every year, more than 105 million tons of coffee are produced in the world (Mussatto et al., 2011; Murthy \& Naidu, 2012b). Coffee cherries industrial processing for the extraction of green coffee beans fit for trade generates several byproducts, depending on the method of processing employed. There are two methods of processing coffee cherries: a dry and a wet method. Depending on the chosen method, dry or wet, the residue receives the name of coffee husk $(\mathrm{CH})$ or coffee pulp (CP), respectively (Fan et al., 2000; Murthy \& Naidu, 2012b). As a result of the dry method, its main byproduct is a residue composed of skin, pulp, mucilage, and parchment, all together in one single fraction called coffee husk. As a result of the wet method, there is a separation of the pulp, mucilage, and parchment, the pulp being the most abundant residue in the process (Esquivel \& Jiménez, 2012).

Lately, coffee residues have interested researchers, not only due to the high amounts which are generated each year, but also because it is expected that such residues have similar properties to those of coffee beans (Ballesteros et al., 2014). Hence, taking into account the presence of bioactive substances in the coffee bean, such as phenolic compounds, chlorogenic acids, for example, there has been a search for an alternative of use for the residues which are originated from the two types of coffee processing, in order to enhance the phenolic compounds content which could be liberated from the byproducts.

Coffee residues have been used in solid state fermentation (SSF) processes, and several studies in the literature have confirmed the growing of different fungi strains, such as Rhizopus, Phanerochaete, Aspergillus, Gibberella fujikuroi, Mucor, Penicillium, and Neurospora (Brand et al., 2000; Pandey et al., 2000; Machado et al., 2002, 2012). This fact has been explained by the presence of a large amount of fermentable sugars in the residues, which constitute an appropriate substrate for yeast and fungi cultivation (Pandey et al., 2000). The use of a Gibberella fujikuroi strain and coffee husk led as a final result to the production of gibberellic acid (Machado et al., 2002). Fruit aromas were produced with Ceratocystis fimbriata from coffee husk supplemented with glucose (Soares et al., 2000). Murthy \& Naidu (2012a) have tested the pulp, husk, tegument, and spent coffee grounds, in the production of xylanase by fungus Penicillium sp., and the results showed higher enzymatic activity when coffee husk was used.

${ }^{1}$ Food Science and Engineering Graduate Program, Food Technology and Engineering Department, Universidade Estadual Paulista "Júlio de Mesquita Filho" - UNESP, São José do Rio Preto, SP, Brazil

${ }^{2}$ Organic Chemistry Department, Nucleus of Bioassays, Biosynthesis, and Ecophysiology of Natural Products, Institute of Chemistry, Universidade Estadual Paulista "Júlio de Mesquita Filho" - UNESP, Araraquara, SP, Brazil

*Corresponding author: ladypalominog@gmail.com 
The production of citric acid by fungus Aspergillus niger was also reported, using as a support the coffee husk moistened with a $\mathrm{NaOH}$ solution, and the production increased in the presence of minerals (Shankaranand \& Lonsane, 1994).

Although it is known that SSF is a good alternative for the production of phenolic compounds and for its content's increase (Martins et al., 2011), this fact has not been closely investigated to what coffee residues are concerned. However, Machado et al. (2012) evaluated seven fungal strains from the genus Aspergillus, Mucor, Penicillium, and Neurospora, regarding their capacity of growing and liberating phenolic compounds from the coffee tegument and spent coffee grounds under solid state cultivation conditions. The results of the study showed that all strains grew in the residue, and Penicillium purpurogenum, Neurospora crassa, and Mucor released the biggest quantity of phenolic compounds.

In the literature, there are no studies which establish the best fermentation conditions with the objective of increasing the phenolic compounds content released from coffee byproducts. Thus, the objective of this study was to evaluate the influence of solid state fungal fermentation in obtaining polyphenols, to determine the total phenols content, to identify and quantify the main phenolic compounds, and to determine the antioxidant activity through the effective concentration $\left(\mathrm{EC}_{50}\right)$ of the extracts. The response surface methodology was chosen to evaluate the possible interactions among the factors which might influence the fermentation process, such as initial moisture content, initial $\mathrm{pH}$ in the fermentation medium, and the incubation temperature.

\section{Materials and methods}

\subsection{Materials}

Chlorogenic acid (CGA), Caffeic acid, Rutin, Quercetin, Gallic acid (GA), and 1, 1-diphenyl-2-picrylhydrazyl (DPPH) were purchased from Sigma-Aldrich (St. Louis, MO, USA). All solvents and reagents used were analytical grade, purchased from Dinâmica (Diadema, SP, Brazil), Vetec (Rio de Janeiro, RJ, Brazil), or Synth (Diadema, SP, Brazil). HPLC grade solvents were provided by J.T.Baker (Phillipsburg, NJ, USA), and deionized water purified was obtained using a Milli-Q system (Millipore, Bedford, MA, USA). Sep-Pak C18 cartridges for solid-phase extraction were purchased from Chromabond ${ }^{\circledast}$ (Bethlehem, PA, USA). The coffee husk ( $\mathrm{CH}$ ) from Robusta variety was provided by Cocam Industry, Companhia de Café Solúvel e Derivados (Catanduva, SP, Brazil). The coffee pulp (CP), also from Robusta variety, was obtained from a coffee producing area in Cauca, Colombia. Before used, the coffee residues were dried at $60{ }^{\circ} \mathrm{C}$ to a constant weight and were then crushed.

\subsection{Microorganism and culture conditions}

The fungal strain Penicillium purpurogenum CCT 2008 donated by the Coleção de Culturas Tropical, Fundação André Tosello (Campinas, SP, Brazil) was used for the present study. It was maintained in refrigerator on potato-dextrose-agar medium at $5{ }^{\circ} \mathrm{C}$ and it was grown at $30^{\circ} \mathrm{C}$. The fermentation inoculum with a concentration of $10^{6}$ spores/g substrate consisted in spores obtained after 7 days from the sporulated culture medium, which were collected in $0.1 \%$ Tween 80 solution and counted in a Neubauer chamber.

\subsection{Solid state fermentation (SSF) and influence of physicochemical parameters}

Previously dried and crushed $\mathrm{CH}$ and $\mathrm{CP}$ substrates were sterilized in a vertical autoclave (Phoenix, Brazil) at $120^{\circ} \mathrm{C}$ for 15 minutes. Sterilized cheese whey was used to humidify the substrate, as an additional source of fermentable sugars (lactose 4.5-5.0\%). Fermentation was carried out in plastic bags, containing the inoculum and $10 \mathrm{~g}$ of sterilized substrate and moistened with cheese whey with the desired moisture level. SSF was conducted for 5 days in accordance with a previous single-parameter study (data not shown). The fermented samples were extracted and the total phenolic compounds content was quantified.

The initial substrate moisture, medium initial $\mathrm{pH}$ and incubation temperature were the chosen physicochemical parameters to evaluate the influence on the phenolic compounds content in $\mathrm{CH}$ and CP. A central composite design (CCD) was employed to analyze the combined effects of these parameters and find the region with the best results. A summary of the variables and their levels of variation is presented in Table 1.

\subsection{Phenolic compounds extraction}

The phenolic compounds present in the fermented material were extracted using the methodology by Ajila et al. (2011) with some modifications. Fermented substrate was weighed to $1.0 \mathrm{~g}$ and $20 \mathrm{~mL}$ of $80 \%$ acetone was added. The samples were placed in Erlenmeyer flasks in a Shaker incubator (Lucadema, Brazil) at $40{ }^{\circ} \mathrm{C}$ and $120 \mathrm{rpm}$ for $30 \mathrm{~min}$, and then centrifuged for $15 \mathrm{~min}$ at $3200 \mathrm{rpm}$ in an Excelsa Baby II centrifuge (Fanem, model 206-R). Supernatant was used when determining the phenolic compounds. Each extraction was carried out in duplicate.

\subsection{Determination of total phenolic content}

Total phenolic compounds content was determined by using the Folin-Ciocalteu method (Singleton \& Rossi, 1965), according to the methodology described by Palomino et al. (2009). Total phenolic compounds content was expressed as equivalents of gallic acid ( $\mathrm{mg}$ of $\mathrm{GA} \cdot \mathrm{g}^{-1}$ substrate). Analyses were carried out in triplicate.

\subsection{Sample preparation before HPLC and antioxidants analysis}

After establishing variable values which yielded the best results in obtaining phenolic compounds from each residue, a new fermentation was carried out through the established

Table 1. Range of variables at different levels for the central composite design.

\begin{tabular}{lccccc}
\hline \multirow{2}{*}{ Independent variables $\mathrm{X}_{\mathrm{i}}$} & \multicolumn{6}{c}{ Levels } \\
\cline { 2 - 6 } & -1.68 & -1 & 0 & +1 & +1.68 \\
\hline $\mathrm{X}_{1}$ Initial moisture content $(\%)$ & 25 & 35 & 50 & 65 & 75 \\
$\mathrm{X}_{2}$ Medium $\mathrm{pH}$ & 4 & 4.4 & 5 & 5.6 & 6 \\
$\mathrm{X}_{3}$ Incubation temperature $\left({ }^{\circ} \mathrm{C}\right)$ & 25 & 27 & 30 & 33 & 35 \\
\hline
\end{tabular}


parameters. Extraction procedure for the fermented material was the same as previously mentioned; in this case, $10.0 \mathrm{~g}$ of each fermented substrate was weighed and $200 \mathrm{~mL}$ of $80 \%$ acetone was added. The extract was concentrated in a rotary evaporator (Tecnal, Brazil) and the resulting sample was lyophilized in a Liotop lyophilizer (Liobras, Brazil) for later storage in solid state and HPLC and antioxidant activity analyses.

Before injecting samples into HPLC, the extracts were submitted to a solid phase extraction (SPE) using Sep-Pak C18 cartridges and the methodology of Ramirez-Coronel et al. (2004) with some modifications as follows: $15 \mathrm{mg}$ extract was suspended in $4 \mathrm{~mL}$ of acetic acid $(2.5 \% \mathrm{v} / \mathrm{v})$ and placed in an ultrasonic bath for $10 \mathrm{~min}$. The cartridges were conditioned with $4 \mathrm{~mL}$ of methanol, followed by $5 \mathrm{~mL}$ of acetic acid $(2.5 \% \mathrm{v} / \mathrm{v})$. The sample was introduced into the cartridge and eluted; then, $8 \mathrm{~mL}$ of acetic acid $(2.5 \% \mathrm{v} / \mathrm{v})$ were added in order to remove the sugars. Polyphenols were eluted with $4 \mathrm{~mL}$ of acetone/water $(6: 4)$ containing acetic acid $(2.5 \% \mathrm{v} / \mathrm{v})$. The polyphenols fraction was collected and evaporated. Finally, the sample was solubilized in $1.5 \mathrm{~mL}$ of methanol/water (7:3), and filtered using nylon membranes to be later analyzed through HPLC-UV/DAD.

\subsection{High-performance liquid chromatography analysis}

Phenolic compounds identification was carried out in a high-performance liquid chromatography model LC-10AD (Shimadzu) coupled to ultraviolet detector in photodiode array, model SPD-M10A (Shimadzu), with a system of acquisition and data treatment LCsolution (Shimadzu). The analytical column used was a Phenomenex ${ }^{\circ}$ Luna $^{\circ} \mathrm{C} 18(250 \mathrm{~mm} \times 4.6 \mathrm{~mm}$ i.d.; $5 \mu \mathrm{m})$. The elution method for main phenolic compounds was based on the methodology by Murthy \& Naidu (2012b) with modifications. The mobile phase used was $5 \%$ acetonitrile in $0.035 \%$ trifluoroacetic acid (TFA) (solvent A) and 80\% acetonitrile in $0.025 \%$ TFA (solvent B). Gradient elution was used, incrementing B from 0 to $20 \%$ in $20 \mathrm{~min}$, and reaching $50 \%$ of B in $50 \mathrm{~min}$. Detection was carried out at 230 and $330 \mathrm{~nm}$.

\subsection{Antioxidant potential}

In order to determine the antioxidant potential, the dry extracts were resuspended in Dimethyl Sulfoxide (DMSO), in final concentration of $4.0 \mathrm{~g} \mathrm{~L}^{-1}$ and stored in refrigerator at $5{ }^{\circ} \mathrm{C}$. Aliquots of the stored solutions from the extracts were diluted in ethanol in concentrations of $10 \mathrm{ppm}$ to $200 \mathrm{ppm}$. The evaluation of the antioxidant activity was conducted according to $\mathrm{DPPH}{ }^{*}$ method described by Brand-Williams et al. (1995) with some modifications. In the 96 -well plate was added $35 \mu \mathrm{L}$ sample and $215 \mu \mathrm{L}$ solution of $\mathrm{DPPH}^{\cdot}\left(8.610^{-5} \mathrm{~mol} / \mathrm{L}\right)$. The plate was incubated in the dark for 30 minutes; subsequently, the absorbance was measured in the UV-Vis Synergy HT Multi-Mode Microplate Reader (BioTek, USA), at $\lambda=515 \mathrm{~nm}$. Measurements of different concentrations of solutions of each extract were realized, all in triplicate. The same procedure was carried out with the standard rutin and quercetin ethanolic solution in concentration range from 0.4 to $8.0 \mathrm{ppm}$, for later comparison of the antioxidant activity. $\mathrm{DPPH}^{\cdot}$ radical scavenging capacity was calculated through Equation 1:
DPPH scavenging $\%=\left(\mathrm{A}_{0}-\mathrm{A}_{\mathrm{s}} / \mathrm{A}_{0}\right) \times 100$

where $\mathrm{A}_{0}$ is the absorption of the blank and $\mathrm{A}_{\mathrm{s}}$ is the absorption of the sample at $515 \mathrm{~nm}$.

The percentage of DPPH• scavenging was then plotted against the sample concentration to calculate graphically the sample concentration necessary to decrease the initial $\mathrm{DPPH}^{*}$ concentration by $50 \%\left(\mathrm{EC}_{50}\right)$.

\subsection{Statistical analyses}

All analyses were carried out using Statistica 7.0 software (StatSoft Inc., Oklahoma, USA). The differences were considered statistically significant for $P<0.05$. All values are presented as mean \pm SD. All determinations were carried out in triplicate.

\section{Results and discussion}

\subsection{Solid state fermentation and optimization of physicochemical parameters}

The fungal growth during the SSF process was observed. It confirmed that $\mathrm{CH}$ and $\mathrm{CP}$ are appropriate byproducts to serve as substrates in fermentative processes, since they contain significant levels of proteins, lipids and sugars. Results of a previous chemical analysis showed that the experimental sample of coffee husk contained (\% w/w): protein (total $\mathrm{N} \times 5.75$ ) 13.62; lipids 2.20 and total sugars 3.01 (Palomino \& Del Bianchi, 2015). Coffee pulp has a similar composition: protein $(9.68 \%)$, lipids $(1.46 \%)$ and total sugars (5.92\%) (Palomino, 2015).

In turn, the cheese whey used to humidify the medium is deproteinized whey, known as whey permeate, a large fraction of lactose (4.5-5.0\%), which is converted into an additional source of fermentable sugars. Using cheese whey can be considered an important advantage in the fermentative process, because a fungal growth was observed without adding synthetic medium, which makes the biotechnological process even more economical.

The experimental design and the results of the experiments conducted through CCD are shown in Table 2.

The obtained results for the response variable were submitted to a multiple regression analysis, being statistically significant the coefficients whose $P$-value was less than 0.05 . The regression was evaluated through analysis of variance (ANOVA), being a significant regression $P<0.05$. In order to construct the response surface, only the statistically significant coefficients of the independent variables were considered.

For coffee husk, the phenolic compounds content was influenced by the linear terms of the three evaluated factors, which resulted in Equation 2.

$Y_{1}=200.77+18.34 X_{1}-12.94 X_{2}+19.89 X_{3}$

where $\mathrm{Y}_{1}$ is the phenolic compounds content in $\mathrm{CH}(\mathrm{mg}$ $\mathrm{GA} / \mathrm{g}$ of $\mathrm{CH}), \mathrm{X}_{1}$ is the initial substrate moisture (\%), $\mathrm{X}_{2}$ is the medium initial $\mathrm{pH}$, and $\mathrm{X}_{3}$ is the incubation temperature $\left({ }^{\circ} \mathrm{C}\right)$. The regression was significant $(P<0.05)$ with $\mathrm{R}^{2}$ of $74.74 \%$. The coefficient of determination $\left(\mathrm{R}^{2}\right)$ suggests that the model 
could explain $74.74 \%$ of the total variation and it is adequate to evaluate the phenolic compounds content behavior regarding the three factors.

From the previous model, response surfaces were generated referring to the effect of initial moisture, medium initial $\mathrm{pH}$, and incubation temperature on the phenolic compounds content, as presented in the Figure 1.

Figure 1a shows the effect of medium initial $\mathrm{pH}$ and the initial substrate moisture on the phenolic compounds content of fermented $\mathrm{CH}$. Higher percentages of initial substrate moisture have a higher influence on the polyphenols content than the increase in the medium $\mathrm{pH}$. Initial moisture between $50-75 \%$ and medium $\mathrm{pH}$ lower than 5 are the best conditions for the increase in the phenolic compounds content. Figure $1 \mathrm{~b}$ depicts that high percentages of initial moisture and high incubation temperatures are the ideal conditions for the increase in polyphenols content. Figure 1c shows the effect of the medium initial $\mathrm{pH}$ and the incubation temperature, showing that temperature between 30-35 ${ }^{\circ} \mathrm{C}$ have an important effect on the polyphenols content, and confirming that the medium $\mathrm{pH}$ must be lower than 5 .

In the coffee pulp, the phenolic compounds content was influenced by the initial substrate moisture and by the incubation temperature. Equation 3 represented the model with the corresponding reparameterization.

$Y_{2}=122.6577+12.231 X_{1}-11.624 X_{3}^{2}$

where $\mathrm{Y}_{2}$ is the phenolic compounds content in $\mathrm{CP}(\mathrm{mg} \mathrm{GA} / \mathrm{g}$ of CP), $\mathrm{X}_{1}$ is the initial substrate moisture (\%), and $\mathrm{X}_{3}$ is the incubation temperature $\left({ }^{\circ} \mathrm{C}\right)$. The regression was significant $(P<0.05)$ with $\mathrm{R}^{2}$ of $83.52 \%$.

From the previous model was generated the response surface referring to the moisture and temperature effects on the phenolic compounds content, as shown in Figure 2. The response surface allows us to observe that an initial moisture between $65-75 \%$ and temperature of approximately $33^{\circ} \mathrm{C}$ constitute the region where there were the most polyphenols.

SSF with Penicillium purpurogenum, using coffee residues $\mathrm{CH}$ and $\mathrm{CP}$ as substrates, showed that the presence of the microorganism and specific fermentation conditions result in an increase in the phenolic compounds content, particularly in $\mathrm{CH}$. The result is in accordance with the one reported by Machado et al. (2012), who used other coffee residues (coffee silverskin and spent coffee grounds), and found that fungus $P$. purpurogenum liberated phenolic compounds through solid state fermentation, reaching values of $7.02\left(\mathrm{mg} \mathrm{g}^{-1}\right.$ spent coffee grounds) and 3.47 ( $\mathrm{mg} \mathrm{g}^{-1}$ coffee silverskin).

Different methodologies of SSF have been showing that the most important variable of the process is the initial moisture content. In this study it was observed that the initial moisture content was a determining factor in polyphenols liberation, being most recommended to be between $50-75 \%$.

Moreover, the results showed that with the initial moisture content, the incubation temperature is another important variable in the process. For $\mathrm{CH}$, the best results in the polyphenols extraction were obtained when the incubation temperature was between $33-35^{\circ} \mathrm{C}$, and, for $\mathrm{CP}$, when it was close to $33^{\circ} \mathrm{C}$. The small variations in the medium initial $\mathrm{pH}$ did not influence significantly the process, when it was kept in the filamentous fungus ideal growth interval, between 4 and 6 .

A new fermentation with each substrate was carried out, where the parameters values already evaluated were in the regions where there were higher phenolic compounds content, to identify the main polyphenols and evaluate the antioxidant capacity of the extracts.

Table 2. Experimental design and results of the central composite design for coffee husk and coffee pulp.

\begin{tabular}{|c|c|c|c|c|c|}
\hline \multirow{2}{*}{ Runs } & \multirow{2}{*}{$\mathrm{X}_{1}$} & \multirow{2}{*}{$\mathrm{X}_{2}$} & \multirow{2}{*}{$\mathrm{X}_{3}$} & \multicolumn{2}{|c|}{ Total polyphenols (mg GA/g residue) } \\
\hline & & & & Coffee husk & Coffee pulp \\
\hline 1 & -1 & -1 & -1 & $161.29 \pm 1.12$ & $101.79 \pm 0.43$ \\
\hline 2 & +1 & -1 & -1 & $181.60 \pm 1.20$ & $113.21 \pm 1.15$ \\
\hline 3 & -1 & +1 & -1 & $150.80 \pm 1.61$ & $92.44 \pm 1.53$ \\
\hline 4 & +1 & +1 & -1 & $174.70 \pm 1.20$ & $113.01 \pm 2.51$ \\
\hline 5 & -1 & -1 & +1 & $188.49 \pm 1.85$ & $107.17 \pm 1.49$ \\
\hline 6 & +1 & -1 & +1 & $252.71 \pm 1.00$ & $117.40 \pm 0.88$ \\
\hline 7 & -1 & +1 & +1 & $182.20 \pm 1.61$ & $93.00 \pm 0.65$ \\
\hline 8 & +1 & +1 & +1 & $237.57 \pm 1.85$ & $113.75 \pm 1.20$ \\
\hline 9 & -1.68 & 0 & 0 & $186.31 \pm 0.22$ & $108.44 \pm 1.30$ \\
\hline 10 & +1.68 & 0 & 0 & $237.81 \pm 1.25$ & $170.31 \pm 0.62$ \\
\hline 11 & 0 & -1.68 & 0 & $240.75 \pm 2.00$ & $117.92 \pm 0.76$ \\
\hline 12 & 0 & +1.68 & 0 & $158.75 \pm 1.32$ & $119.92 \pm 0.76$ \\
\hline 13 & 0 & 0 & -1.68 & $183.58 \pm 1.53$ & $96.75 \pm 1.00$ \\
\hline 14 & 0 & 0 & +1.68 & $230.58 \pm 0.58$ & $95.75 \pm 1.32$ \\
\hline 15 & 0 & 0 & 0 & $217.58 \pm 1.04$ & $122.75 \pm 1.50$ \\
\hline 16 & 0 & 0 & 0 & $216.42 \pm 2.52$ & $122.75 \pm 1.80$ \\
\hline 17 & 0 & 0 & 0 & $211.92 \pm 2.47$ & $120.25 \pm 2.29$ \\
\hline
\end{tabular}

Results are expressed as mean \pm standard deviation; $\mathrm{n}=3$. 

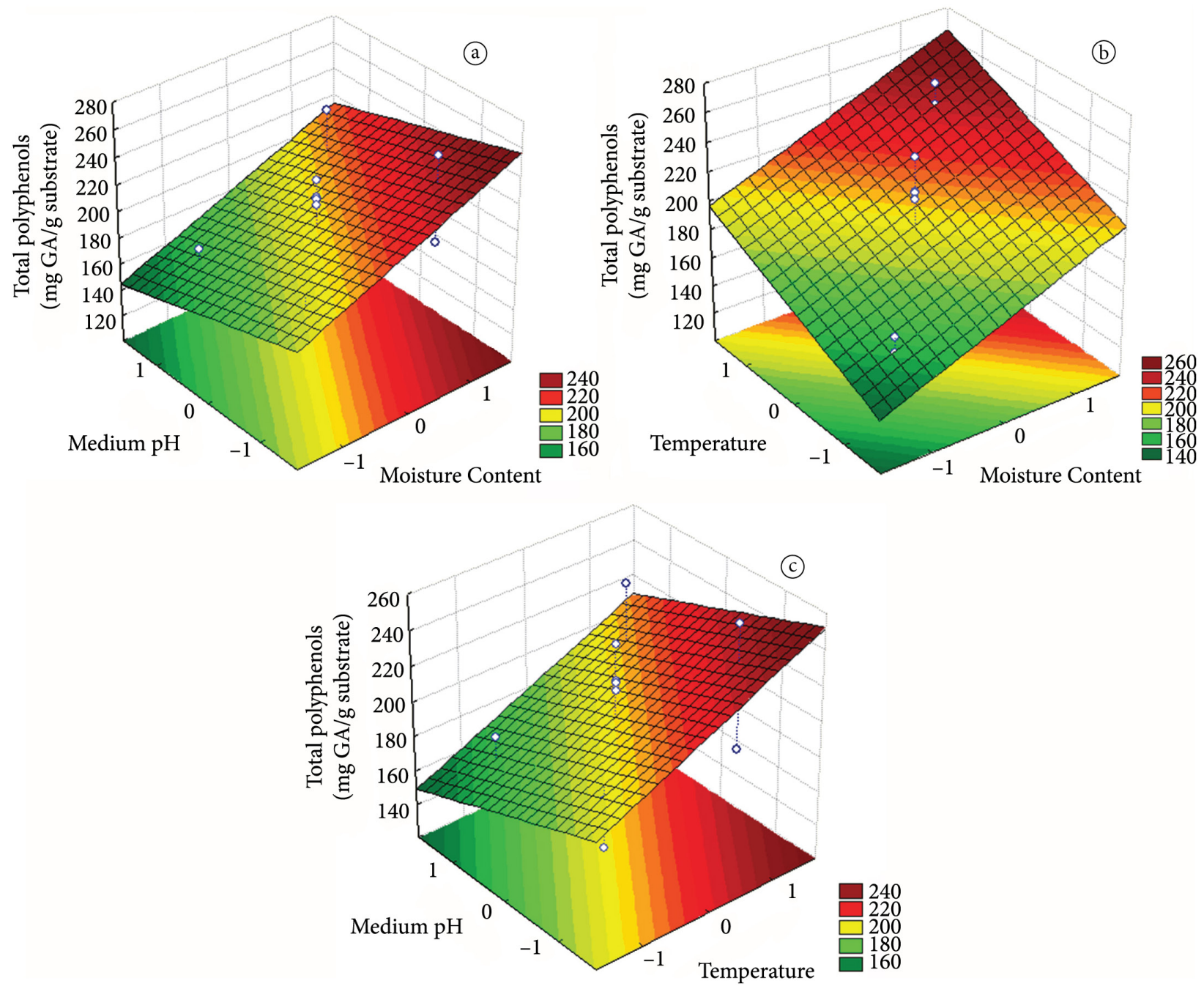

Figure 1. Effect of physicochemical parameters on content of total polyphenols by P. purpurogenum on coffee husk, where (a) initial moisture $\left(\mathrm{X}_{1}\right) \times$ medium initial $\mathrm{pH}\left(\mathrm{X}_{2}\right)$; (b) initial moisture $\times$ incubation temperature $\left(\mathrm{X}_{3}\right) ;(\mathrm{c})$ incubation temperature $\times$ medium initial $\mathrm{pH}$. $(\mathrm{Center}$ point $\left.\mathrm{X}_{1}=50 \%, \mathrm{X}_{2}=5, \mathrm{X}_{3}=30^{\circ} \mathrm{C}\right)$.

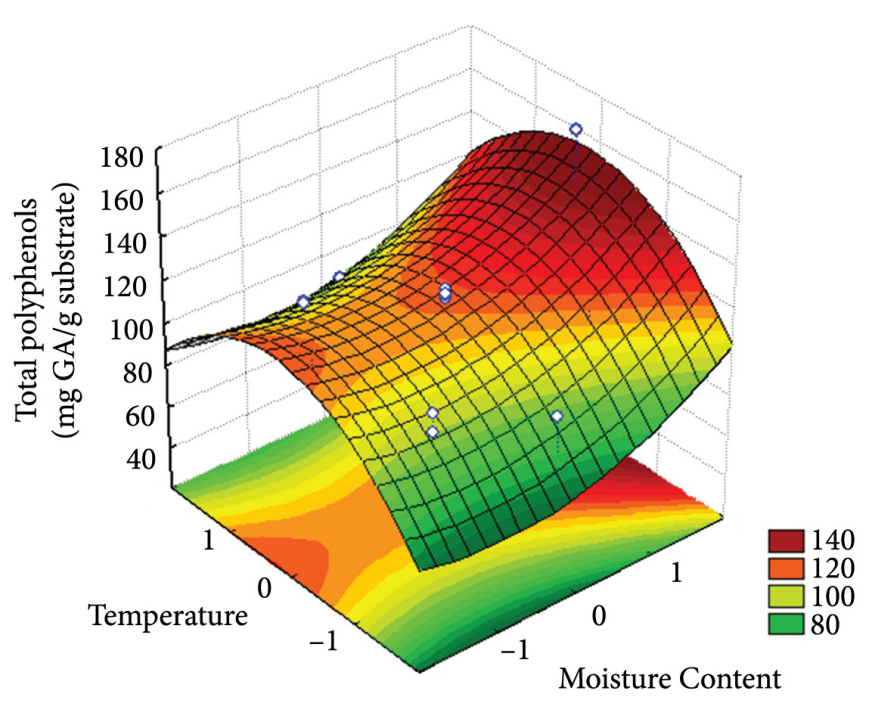

Figure 2. Effect of incubation temperature and initial moisture on content of total polyphenols by $P$. purpurogenum on coffee pulp. (Center point $\mathrm{X}_{1}=50 \%, \mathrm{X}_{2}=5, \mathrm{X}_{3}=30^{\circ} \mathrm{C}$ ).

\subsection{High-performance liquid chromatography analysis}

Polyphenols were quantified using the external standard method. Analytical curves were used to determine the correlation between the measured signal, in this case, the area, and the concentration of the species to be quantified. Thus, the identification of each compound was carried out using the retention time and UV spectrum, since polyphenols absorb in the ultraviolet region. According to the literature, polyphenols derived from cinnamic acid exhibited two intense bands with maximum absorption in the regions 219 and $325 \mathrm{~nm}$, and two shoulders at 245 and $295 \mathrm{~nm}$ (Lee, 2000; Rohr et al., 2000). Thus, the identified phenolic acids were chlorogenic acid and caffeic acid. Rutin was also identified, flavonol which showed two characteristic bands of absorption, the first with an maximum absorption at $255 \mathrm{~nm}$, and the second around $354 \mathrm{~nm}$ (Rodrigues, 2007).

Figure 3 shows the HPLC chromatogram which is typical of the extracts after the husk fermentation of Robusta and coffee pulp in the established chromatography conditions. 
The phenolic compounds quantities found in the samples are shown in Table 3. Significant amounts of chlorogenic and caffeic acid, and a lower content of rutin were observed. Chlorogenic acid was the most abundant phenolic compound in both fermented residues, with a higher amount in the $\mathrm{CH}$ extract. Chlorogenic acid is the most abundant phenolic acid in the green coffee bean (Madhava-Naidu et al., 2008), which could explain its presence in the byproducts.

The phenolic compounds content in coffee residues in natura have been studied. The content of chlorogenic acid varied in the different coffee residues; $24 \mathrm{mg} / \mathrm{g}$ were found in the coffee pulp, whereas $25 \mathrm{mg} / \mathrm{g}$ were found in the husk, $30 \mathrm{mg} / \mathrm{g}$ in the coffee silverskin, and $23 \mathrm{mg} / \mathrm{g}$ in the spent coffee grounds (Murthy \& Naidu, 2012c). Lower chlorogenic acid contents in the pulp of different coffee species were reported, ranging from 4.2 to $16.1 \mathrm{mg} / \mathrm{g}$ (Clifford \& Ramirez-Martinez, 1991).

Therefore, in this study it was observed that applying SSF is more efficient when obtaining phenolic compounds from coffee residues, since the chlorogenic acid values in the coffee husks and pulp are 132.50 and $22.83 \mathrm{mg} / \mathrm{g}$ respectively.

\subsection{Antioxidant potential}

The antioxidant capacity of fermented $\mathrm{CH}$ and $\mathrm{CP}$ extracts was evaluated in terms of radical hydrogen donation or radical scavenging ability, using rutin and quercetin as reference antioxidant compounds.
DPPH $\cdot$ absorbance with the extracts was measured after $30 \mathrm{~min}$ of reaction and through absorbance readings for each sample, the values of \% DPPH' scavenging were calculated to obtain the values of $\mathrm{EC}_{50}$ (Table 4). This parameter represents the necessary concentration of the sample to scavenge $50 \%$ $\mathrm{DPPH}^{\bullet}$ radicals. Several tests were carried out in order to evaluate the appropriate concentration range for each extract to reach the $\mathrm{EC}_{50}$ value.

The lower the value for $\mathrm{EC}_{50}$, the higher the antioxidant capacity of the sample. Thus, the comparison of values indicated that the fermented $\mathrm{CH}$ extract had higher free-radical scavenging capacity than the fermented CP extract. This result is in accordance with results obtained in the quantification of phenolic compounds through HPLC, where it was observed that the fermented $\mathrm{CH}$ extract showed a higher phenolic compounds content than the $\mathrm{CP}$ extract, proving the correlation between the polyphenols content and the antioxidant activity. The standards showed higher antioxidant capacity than the extracts. This fact could be partly related to the purity of standards, whereas the crude extract contains other compounds which are not necessarily proton donors, for example, sugars connected with active compounds (Zeraik et al., 2012).

In this study, the antioxidant capacity of extracts can be assigned to the presence of phenolic substances. The antioxidant capacity of chlorogenic acid has been reported in different studies. For example, chlorogenic acid isomers isolated from dried prune

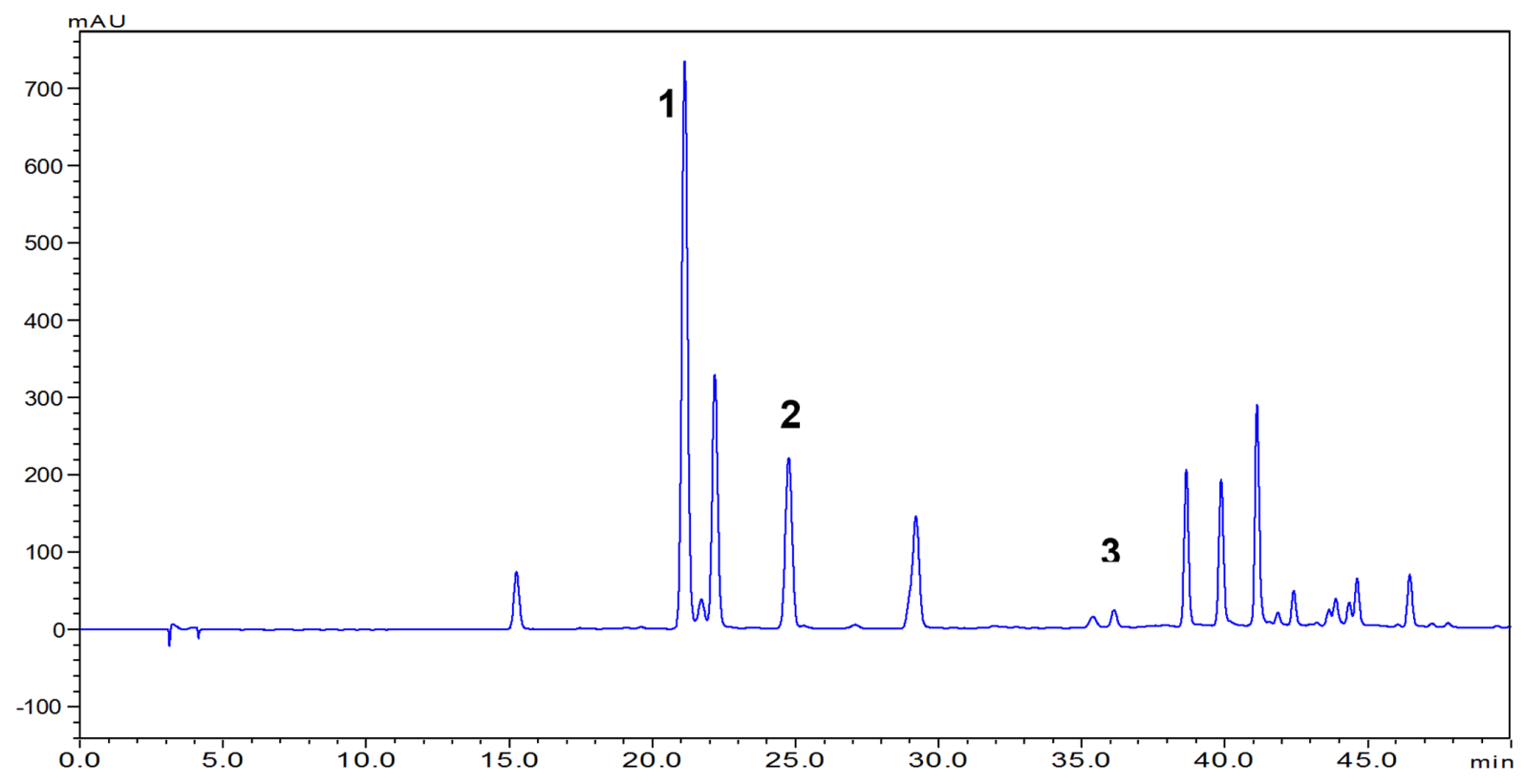

Figure 3. Typical HPLC chromatograph of Robusta coffee husk after fermentation where: 1, chlorogenic acid; 2 , caffeic acid; 3 , rutin.

Table 3. Content of phenolic compounds in the fermented material.

\begin{tabular}{cccc}
\hline \multirow{2}{*}{ Sample } & \multicolumn{3}{c}{ Content } \\
\cline { 2 - 4 } & Chlorogenic acid & Caffeic acid & Rutin \\
\hline Coffee husk $(\mathrm{CH})$ & $132.50 \pm 0.7$ & $28.27 \pm 0.62$ & $8.26 \pm 0.32$ \\
Coffee pulp (CP) & $22.83 \pm 0.16$ & $4.29 \pm 0.24$ & $1.95 \pm 0.27$ \\
\hline
\end{tabular}

Each value is the mean $(\mathrm{mg} / \mathrm{g}$ sample) of three replications \pm standard deviation. 
Table 4. Results of the $\mathrm{DPPH}^{\cdot}$ assay of the fermented samples and standards compounds.

\begin{tabular}{lccc}
\hline \multicolumn{1}{c}{ Samples } & $\begin{array}{c}\text { Concentration } \\
(\mathrm{ppm})\end{array}$ & $\begin{array}{c}\text { \% scavenged } \\
\mathrm{DPPH}^{\cdot}\end{array}$ & $\mathrm{EC}_{50} \pm$ s.d. $(\mathrm{ppm})$ \\
\hline $\begin{array}{l}\text { Coffee husk } \\
(\mathrm{CH})\end{array}$ & $10.0-80.0$ & $34.8-82.6$ & $27.4 \pm 0.14$ \\
Coffee pulp & $10.0-80.0$ & $26.0-77.9$ & $36.4 \pm 0.78$ \\
$(\mathrm{CP})$ & & & \\
Rutin & $0.4-8.0$ & $6.0-62.8$ & $5.7 \pm 0.11$ \\
Quercetin & $0.4-8.0$ & $6.5-85.3$ & $4.9 \pm 0.06$ \\
\hline \multicolumn{2}{l}{ Results are expressed as mean \pm standard deviation; $\mathrm{n}=3}$.
\end{tabular}

showed antioxidant activity when evaluated their scavenging activity on superoxide anion radicals and their inhibitory effect against oxidation of methyl linoleate (Nakatani et al., 2000). Chlorogenic acid, which is found in carrot, burdock, apricot, and black prune extracts, is a potent inhibitor of lipid peroxidation in vitro and also showed a possible anticarcinogenic activity in vivo (Kasai et al., 2000). Isomers derived from chlorogenic acid isolated from bamboo leaves showed high free-radical and superoxide radical scavenging capacity, besides inhibiting the lipid peroxidation (Kweon et al., 2001).

The antioxidant capacity of caffeic acid is due to its chemical structure, since the highest antioxidant potential of cinnamic acids is found when there are two hydroxyls in positions 3 and 4 (Soares, 2002). The caffeic acid has been proved an effective antioxidant in different in vitro tests. Gülçin (2006) evaluated its antioxidant potency using different methods: the ferric thiocyanate, reducing power, $\mathrm{ABTS}^{\bullet+}$ and $\mathrm{DPPH}^{\bullet}$ radical scavenging, superoxide anion radical scavenging, and the metal chelating activity, which showed that the caffeic acid was effective when compared to conventional antioxidants, such as BHA and $\mathrm{BHT}$, and to natural antioxidants, such as $\boldsymbol{\alpha}$-tocopherol. Rutin is a bioflavonoid of recognized bioactivities; it presents properties both as a free-radical scavenging agent, and as metal chelating, acting positively as an anti-inflammatory and to treat diseases such as ischemia, anemia, and arthritis (Afanas'ev et al., 1989; Guardia et al., 2001; Kessler et al., 2003).

These results suggest the possibility of using both residues to obtain antioxidant compounds, since such compounds contain several applications in the food, cosmetics, and pharmaceutical areas (Ao et al., 2011; Ballesteros et al., 2014).

\section{Conclusions}

A study of the most influential variables when obtaining phenolic compounds through a solid state fermentation by Penicillium purpurogenum is reported for the first time. This study allows to conclude that coffee industry residues are appropriate substrates for the growth of the microorganism, and that SSF influences positively the obtainment of phenolic compounds, particularly when the initial moisture content is between $50-75 \%$ and the incubation temperature is approximately to $33^{\circ} \mathrm{C}$. Under these conditions, the obtained extracts after the fermentation showed high amounts of chlorogenic acid, besides caffeic acid and rutin, though in lower amounts. Also, these extracts showed a free-radical scavenging capacity. This study is a support for new studies in this area and opens up new possibilities for the use of residues, due to the growing demand of phenolic compounds by the food and pharmaceutical industries.

\section{Acknowledgements}

The authors would like to acknowledge to the program Paedex from São Paulo State University (Brazil) for scholarships. The authors also acknowledge the Núcleo de Pesquisa NuBBE, Institute of Chemistry, Organic Chemistry Department, São Paulo State University (Brazil), for lending their laboratories for the HPLC and antioxidant activity analyses.

\section{References}

Afanas'ev, I. B., Dcrozhko, A. I., Brodskii, A. V., Kostyuk, V. A., \& Potapovitch, A. I. (1989). Chelating and free radical scavenging mechanisms of inhibitory action of rutin and quercetin in lipid peroxidation. Biochemical Pharmacology, 38(11), 1763-1769. http:// dx.doi.org/10.1016/0006-2952(89)90410-3. PMid:2735934.

Ajila, C. M., Brar, S. K., Verma, M., Tyagi, R. D., \& Valéro, J. R. (2011). Solid-state fermentation of apple pomace using Phanerocheate chrysosporium: liberation and extraction of phenolic antioxidants. Food Chemistry, 126(3), 1071-1080. http://dx.doi.org/10.1016/j. foodchem.2010.11.129.

Ao, C., Higa, T., Khanh, T. D., Upadhyay, A., \& Tawata, S. (2011). Antioxidant phenolic compounds from Smilax sebeana Miq. LWT - Food Science and Technology, 44(7), 1681-1686. http://dx.doi. org/10.1016/j.lwt.2011.02.001.

Ballesteros, L. F., Teixeira, J. A., \& Mussatto, S. I. (2014). Chemical, functional, and structural properties of spent coffee grounds and coffee silverskin. Food and Bioprocess Technology, 7(12), 3493-3503. http://dx.doi.org/10.1007/s11947-014-1349-z.

Brand, D., Pandey, A., Roussos, S., \& Soccol, C. R. (2000). Biological detoxification of coffee husk by filamentous fungi using a solid state fermentation system. Enzyme and Microbial Technology, 27(12), 127-133. http://dx.doi.org/10.1016/S0141-0229(00)00186-1. PMid:10862912.

Brand-Williams, W., Cuvelier, M. E., \& Berset, C. (1995). Use of a free radical method to evaluate antioxidant activity. $L W T$ - Food Science and Technology, 28(1), 25-30. http://dx.doi.org/10.1016/ S0023-6438(95)80008-5.</jrn>.

Clifford, M. N., \& Ramirez-Martinez, J. R. (1991). Phenols and caffeine in wet-processed coffee beans and coffee pulp. Food Chemistry, 40(1), 35-42. http://dx.doi.org/10.1016/0308-8146(91)90017-I.

Esquivel, P., \& Jiménez, V. M. (2012). Functional properties of coffee and coffee by-products. Food Research International, 46(2), 488-495. http://dx.doi.org/10.1016/j.foodres.2011.05.028.

Fan, L., Pandey, A., Mohan, R., \& Soccol, C. R. (2000). Use of various coffee industry residues for the cultivation of Pleurotus ostreatus in solid state fermentation. Acta Biotechnologica, 20(1), 41-52. http:// dx.doi.org/10.1002/abio.370200108.

Guardia, T., Rotelli, A. E., Juarez, A. O., \& Pelzer, L. E. (2001). Antiinflammatory properties of plant flavonoids. Effects of rutin, quercetin and hesperidin on adjuvant arthritis in rat. Farmaco, 56(9), 683-687. http://dx.doi.org/10.1016/S0014-827X(01)01111-9. PMid:11680812.

Gülçin, I. (2006). Antioxidant activity of caffeic acid (3,4-dihydroxycinnamic acid). Toxicology, 217(2-3), 213-220. http://dx.doi.org/10.1016/j. tox.2005.09.011. PMid:16243424. 
Kasai, H., Fukada, S., Yamaizumi, Z., Sugie, S., \& Mori, H. (2000). Action of chlorogenic acid in vegetables and fruits as an inhibitor of 8-hydroxydeoxyguanosine formation in vitro and in a rat carcinogenesis model. Food and Chemical Toxicology, 38(5), 467-471. http://dx.doi.org/10.1016/S0278-6915(00)00014-4. PMid:10762733.

Kessler, M., Ubeaud, G., \& Jung, L. (2003). Anti- and pro-oxidant activity of rutin and quercetin derivatives. The Journal of Pharmacy and Pharmacology, 55(1), 131-142. http://dx.doi.org/10.1211/002235702559. PMid:12625877.

Kweon, M.-H., Hwang, H.-J., \& Sung, H.-C. (2001). Identification and antioxidant activity of novel chlorogenic acid derivatives from bamboo (Phyllostachys edulis). Journal of Agricultural and Food Chemistry, 49(10), 4646-4655. http://dx.doi.org/10.1021/jf010514x. PMid:11600002.

Lee, H. (2000). HPLC analysis of phenolics compounds. In L. Nollet (Ed.), Food analysis by HPLC (pp. 775-824). New York: Marcel Dekker.

Machado, C. M. M., Soccol, C. R., de Oliveira, B. H., \& Pandey, A. (2002). Gibberellic acid production by solid-state fermentation in coffee husk. Applied Biochemistry and Biotechnology, 102-103(16), 179-191. http://dx.doi.org/10.1385/ABAB:102-103:1-6:179. PMid:12396121.

Machado, E. M. S., Rodriguez-Jasso, R. M., Teixeira, J., \& Mussatto, S. I. (2012). Growth of fungal strains on coffee industry residues with removal of polyphenolic compounds. Biochemical Engineering Journal, 60, 87-90. http://dx.doi.org/10.1016/j.bej.2011.10.007.

Madhava Naidu, M., Sulochanamma, G., Sampathu, S. R., \& Srinivas, P. (2008). Studies on extraction and antioxidant potential of green coffee. Food Chemistry, 107(1), 377-384. http://dx.doi.org/10.1016/j. foodchem.2007.08.056.

Martins, S., Mussatto, S. I., Martínez-Avila, G., Montañez-Saenz, J., Aguilar, C. N., \& Teixeira, J. A. (2011). Bioactive phenolic compounds: production and extraction by solid-state fermentation: a review. Biotechnology Advances, 29(3), 365-373. http://dx.doi.org/10.1016/j. biotechadv.2011.01.008. PMid:21291993.

Murthy, P. S., \& Naidu, M. M. (2012a). Production and application of xylanase from Penicillium sp. utilizing coffee by-products. Food and Bioprocess Technology, 5(2), 657-664. http://dx.doi.org/10.1007/ s11947-010-0331-7.

Murthy, P. S., \& Naidu, M. M. (2012b). Recovery of phenolic antioxidants and functional compounds from coffee industry by-products. Food and Bioprocess Technology, 5(3), 897-903. http://dx.doi.org/10.1007/ s11947-010-0363-z.

Murthy, P. S., \& Naidu, M. M. (2012c). Sustainable management of coffee industry by-products and value addition: a review. Resources, Conservation and Recycling, 66, 45-58. http://dx.doi.org/10.1016/j. resconrec.2012.06.005.

Mussatto, S. I., Machado, E. M. S., Martins, S., \& Teixeira, J. A. (2011). Production, composition, and application of coffee and its industrial residues. Food and Bioprocess Technology, 4(5), 661-672. http:// dx.doi.org/10.1007/s11947-011-0565-z.

Nakatani, N., Kayano, S., Kikuzaki, H., Sumino, K., Katagiri, K., \& Mitani, T. (2000). Identification, quantitative determination, and antioxidative activities of chlorogenic acid isomers in prune (Prunus domestica L.). Journal of Agricultural and Food Chemistry, 48(11), 5512-5516. http://dx.doi.org/10.1021/jf000422s. PMid:11087511.

Palomino, L. R. (2015). Avaliação da influência da fermentação fúngica em estado sólido na obtenção de compostos fenólicos a partir de resíduos de café (Doctoral thesis). Instituto de Biociências, Letras e Ciências Exatas, Universidade Estadual Paulista, São José do Rio Preto.

Palomino, L. R., \& Del Bianchi, V. L. (2015). Efeito da fermentação fúngica no teor de compostos fenólicos em casca de café robusta. Semina: Ciências Agrárias, 36(2), 777-786. http://dx.doi.org/10.5433/16790359.2015v36n2p777.

Palomino, L. R., García, C. M., Gil, J. H., Rojano, B. A., \& Durango, D. L. (2009). Determinación del contenido de fenoles y evaluación de la actividad antioxidante de propóleos recolectados en el departamento de Antioquia (Colombia). VITAE, 16(3), 388-395.

Pandey, A., Soccol, C., Nigam, P., Brand, D., Mohan, R., \& Roussos, S. (2000). Biotechnological potential of coffee pulp and coffee husk for bioprocesses. Biochemical Engineering Journal, 6(2), 153-162. http://dx.doi.org/10.1016/S1369-703X(00)00084-X. PMid:10959086.

Ramirez-Coronel, M. A., Marnet, N., Kumar-Kolli, V. S., Roussos, S., Guyot, S., \& Augur, C. (2004). Characterization and estimation of proanthocyanidins and other phenolics in coffee pulp (Coffea arabica) by thiolysis-high-performance liquid chromatography. Journal of Agricultural and Food Chemistry, 52(5), 1344-1349. http://dx.doi. org/10.1021/jf035208t. PMid:14995144.

Rodrigues, C. M. (2007). Caracterização quali e quantitativa de metabólitos secundários em extratos vegetais (Doctoral thesis). Instituto de Química, Universidade Estadual Paulista, Araraquara.

Rohr, G. E., Meier, B., \& Sticher, O. (2000). Evaluation of different detection modes for the analysis of procyanidins in leaves and flowers of Crataegus spp. Part I: diode array and electrochemical detection. Phytochemical Analysis, 11(2), 106-112. http://dx.doi.org/10.1002/ (SICI)1099-1565(200003/04)11:2<106::AID-PCA496>3.0.CO;2-O.

Shankaranand, V. S., \& Lonsane, B. K. (1994). Coffee husk: an inexpensive substrate for production of citric acid by Aspergiilus niger in a solid-state fermentation system. World Journal of Microbiology \& Biotechnology, 10(2), 165-168. http://dx.doi.org/10.1007/BF00360879. PMid:24420939.

Singleton, V. L., \& Rossi, J. A. (1965). Colorimetry of total phenolics with phosphomolybdic-phosphotungstic acid reagents. American Journal of Enology and Viticulture, 16(3), 144-158.

Soares, M., Christen, P., Pandey, A., \& Soccol, C. R. (2000). Fruity flavour production by Ceratocystis fimbriata grown on coffee husk in solid-state fermentation. Process Biochemistry, 35(8), 857-861. http://dx.doi.org/10.1016/S0032-9592(99)00144-2.

Soares, S. E. (2002). Ácidos fenólicos como antioxidantes. Revista de Nutrição, 15(1), 71-81.

Zeraik, M. L., Yariwake, J. H., Wauters, J.-N., Tits, M., \& Angenot, L. (2012). Analysis of passion fruit rinds (Passiflora edulis): isoorientin quantification by HPTLC and evaluation of antioxidant (radical scavenging) capacity. Quimica Nova, 35(3), 541-545. http://dx.doi. org/10.1590/S0100-40422012000300019. 